\title{
Fitomassa de raízes e da parte aérea da cana-de-açúcar relacionada à adubação nitrogenada de plantio
}

\author{
Rafael Otto(1), Henrique Coutinho Junqueira Franco(2), Carlos Eduardo Faroni(3),
} André César Vitti ${ }^{(4)}$ e Paulo Cesar Ocheuze Trivelin ${ }^{(2)}$

\begin{abstract}
(1)Universidade de São Paulo (USP), Escola Superior de Agricultura Luiz de Queiroz, Departamento de Ciência do Solo, Caixa Postal 96, CEP 13400-970, Piracicaba, SP. E-mail: rotto@esalq.usp.br (2)USP, Centro de Energia Nuclear na Agricultura, Laboratório de Isótopos Estáveis, Caixa Postal 96, CEP 13400-970 Piracicaba, SP. E-mail: hjfranco@cena.usp.br, pcotrive@cena.usp.br ${ }^{(3)}$ Centro de Tecnologia Canavieira, Bairro Santo Antônio, Caixa Postal 162, CEP 13400-970 Piracicaba, SP. E-mail: cfaroni@ctc.com.br (4)Agência Paulista de Tecnologia dos Agronegócios, Polo Regional Centro Sul, Rodovia SP 127, Km 30, Vila Fátima, CEP 13400-970 Piracicaba, SP. E-mail: acvitti@apta.sp.gov.br
\end{abstract}

Resumo - O objetivo deste trabalho foi avaliar o desenvolvimento de raízes e da parte aérea da cana-de-açúcar (Saccharum spp.), no ciclo cana-planta, em resposta à aplicação de nitrogênio (N) no sulco de plantio. Dois experimentos, um em Latossolo Vermelho-Amarelo eutrófico e outro em Latossolo Vermelho distrófico, foram realizados em delineamento de blocos ao acaso, com quatro repetições, com um tratamento sem $\mathrm{N}$ (controle) e os tratamentos com 40, 80 e $120 \mathrm{~kg} \mathrm{ha}^{-1}$ de $\mathrm{N}$ na forma de ureia, aplicados no sulco de plantio. A massa de raízes e da parte aérea foi quantificada em três épocas (outubro de 2005, fevereiro de 2006 e em junho/julho de 2006). A parte aérea foi coletada em $2 \mathrm{~m}$ da linha, e as raízes foram coletadas com uma sonda de $0,055 \mathrm{~m}$ de diâmetro interno, até $0,6 \mathrm{~m}$ de profundidade. A adubação nitrogenada de plantio incrementou o crescimento de raízes e da parte aérea da cana-de-açúcar no Latossolo Vermelho-Amarelo. Entretanto, não houve incremento desse crescimento no Latossolo Vermelho onde grande quantidade de $\mathrm{N}$ orgânico foi incorporada ao solo por meio de resíduos culturais. A fase de maior desenvolvimento de raízes, em cana-planta de ano e meio, foi de outubro a fevereiro, com diminuição da massa de raízes de fevereiro a julho.

Termos para indexação: Saccharum spp., cana-planta, nitrogênio.

\section{Sugarcane root and shoot phytomass related to nitrogen fertilization at planting}

\begin{abstract}
This work evaluated the root and shoot sugarcane (Saccharum spp.) development in plant cane cycle, related to nitrogen $(\mathrm{N})$ rates applied at planting. Two experiments were carried out using randomized block designs, one in a Typic Eutrustox and other in an Arenic Kandiustults. Treatments were a control without $\mathrm{N}$, and 40, 80 and $120 \mathrm{~kg} \mathrm{ha}^{-1} \mathrm{~N}$ applied in furrow at planting, with four replicates. The root and shoot masses were evaluated in three periods (October 2005, February 2006 and June/July 2006). Shoots were collected in $2 \mathrm{~m}$ of furrow, and the roots were collected using a probe (internal diameter of $0.055 \mathrm{~m}$ ) until $0.6 \mathrm{~m}$ depth. The nitrogen fertilization at planting increased the development of cane roots and shoots in Typic Eutrustox. However, there was no growth increase of sugarcane roots and shoots in the Arenic Kandiustults where a large amount of organic $\mathrm{N}$ from cultural residues had been incorporated into the soil. The phase of larger root development of one and half year old plant cane was from October to February, with decrease of the root mass from February to July.
\end{abstract}

Index terms: Saccharum spp., plant cane, nitrogen.

\section{Introdução}

No Brasil, nas mais diversas condições de clima e solo, grande número de experimentos realizados mostraram que a resposta da cana-planta ao nitrogênio (N)é menor e menos frequente que a observada em canasoca (Albuquerque \& Marinho, 1983; Zambello Júnior \& Azeredo, 1983; Cantarella \& Raij, 1985; Azeredo et al., 1986; Prado \& Pancelli, 2008). Há trabalhos que evidenciam a resposta da cana-planta à fertilização nitrogenada (Korndörfer et al., 1997; Orlando Filho et al., 1999; Trivelin et al., 2002), especialmente quando a análise conjunta de experimentos é realizada (Albuquerque \& Marinho, 1983; Cantarella et al., 2007).

Apesar da importância do sistema radicular para o crescimento da cultura, poucos trabalhos avaliaram, em condições de campo, o desenvolvimento radicular da cana-de-açúcar. Isso se deve, provavelmente, à dificuldade de avaliação e à variabilidade dos resultados obtidos em condições de campo. Em trabalhos desenvolvidos em vasos com solo arenoso, na condição 
de cana-planta de ano (Trivelin et al., 2002) e cana-planta de ano e meio (Bologna-Campbell, 2007), observou-se aumento linear na massa de matéria seca da cultura (parte aérea e subterrânea) e no acúmulo de $\mathrm{N}$, em consequência da adubação nitrogenada de plantio. Franco et al. (2007) evidenciaram maior acúmulo de macronutrientes, com a aplicação de $\mathrm{N}$, em vasos, no sistema radicular da cana-de-açúcar (cana-planta de ano).

Em condições de campo, Sampaio et al. (1987) observaram aumento na massa de raízes de cana-deaçúcar, aos 6 e 16 meses após o plantio, pela aplicação de $60 \mathrm{~kg} \mathrm{ha}^{-1}$ de N. Thorburn et al. (2003) mostraram que a disponibilidade de $\mathrm{N}$ mineral afetou a distribuição das raízes de cana-de-açúcar.

O maior crescimento de raízes pode favorecer a produtividade das soqueiras subsequentes. Vitti et al. (2007) constataram efeito residual da adubação nitrogenada de terceira soca, na produtividade da quarta soca, proporcionado pelo maior crescimento das raízes e maior acúmulo de nutrientes nas raízes nos tratamentos fertilizados com $\mathrm{N}$.

Portanto, há indícios de que a resposta à adubação nitrogenada em cana-planta esteja associada ao maior desenvolvimento do sistema radicular e ao maior acúmulo de nutrientes, tanto nas raízes, quanto na parte aérea.

Além disso, o crescimento das raízes relacionase diretamente às condições do solo, que proporciona plasticidade na forma e no tamanho do sistema radicular. O tamanho e a distribuição do sistema radicular são diretamente afetados pela distribuição e disponibilidade da água, o que causa diferenças na capacidade das plantas de explorar camadas mais profundas do solo (Smith et al., 2005). Smith (1998) verificou que com a remoção de $50 \%$ das raízes das plantas de cana-deaçúcar, o uso da água e a taxa de alongamento da planta diminuíram apenas $10 \%$, o que evidencia que a cana-de- açúcar tem mais raízes do que necessita para atingir seu máximo crescimento.

Assim, a manutenção de grande massa de raízes resulta em gasto excessivo de energia metabólica e tem consequências negativas sobre o crescimento das plantas e sobre a produtividade. A manutenção de pequena massa radicular com formação de raízes novas, antes dos períodos críticos de umidade, pode contribuir para a manutenção da produtividade (Vasconcelos, 2002).

O objetivo deste trabalho foi avaliar o desenvolvimento de raízes e da parte aérea da cana-de-açúcar, no ciclo de cana-planta, em resposta à aplicação de $\mathrm{N}$ no sulco de plantio.

\section{Material e Métodos}

Os experimentos foram realizados nos municípios de Jaboticabal, SP, na Usina Santa Adélia (USA), e de Pirassununga, SP, na Usina São Luiz (USL), com a cultivar de cana-de-açúcar (Saccharum officinarum L.) SP81 3250. A área experimental da USA situa-se a $21^{\circ} 19^{\prime} 98^{\prime \prime} \mathrm{S}, 48^{\circ} 19^{\prime} 3^{\prime \prime} \mathrm{W}$, e à altitude de $600 \mathrm{~m}$. A área experimental da USL está a $21^{\circ} 55^{\prime} 54^{\prime \prime}, 47^{\circ} 10^{\prime} 54^{\prime \prime} \mathrm{W}$, e à altitude de $650 \mathrm{~m}$.

$\mathrm{Na}$ USL, o solo é um Latossolo Vermelho-Amarelo eutrófico (LVAe) e, na USA, um Latossolo Vermelho distrófico (LVd) (Santos et al., 2006). A caracterização dos solos (Tabela 1) foi realizada em amostras indeformadas, coletadas nos horizontes do perfil de uma trincheira em julho de 2006, para a determinação da densidade do solo, pelo método do anel volumétrico (Blake \& Hartge, 1986), e em amostras deformadas, coletadas para análise química (Raij et al., 2001) e granulométrica, pelo método da pipeta (Gee \& Or, 2002).

$\mathrm{O}$ delineamento experimental foi o de blocos ao acaso, com quatro tratamentos $\left(0,40,80\right.$ e $\left.120 \mathrm{~kg} \mathrm{ha}^{-1} \mathrm{de} \mathrm{N}\right) \mathrm{e}$

Tabela 1. Caracterização química e física dos solos das Usinas São Luiz e Santa Adélia.

\begin{tabular}{|c|c|c|c|c|c|c|c|c|c|c|c|c|}
\hline $\begin{array}{l}\text { Horizonte } \\
\text { diagnóstico }\end{array}$ & $\begin{array}{c}\mathrm{pH} \\
\mathrm{H}_{2} \mathrm{O}\end{array}$ & $\begin{array}{c}\mathrm{MO} \\
\left(\mathrm{g} \mathrm{kg}^{-1}\right) \\
\end{array}$ & $\begin{array}{c}\mathrm{P} \\
\left(\mathrm{mg} \mathrm{kg}^{-1}\right)\end{array}$ & K & $\mathrm{Ca}$ & $\begin{array}{l}\mathrm{Mg} \\
-(\mathrm{n}\end{array}$ & $\begin{array}{l}\mathrm{A} \\
\mathrm{Kg}^{-1}\end{array}$ & $\mathrm{H}+\mathrm{Al}$ & $\begin{array}{c}\mathrm{T} \\
---- \\
\end{array}$ & $\begin{array}{l}\mathrm{V} \\
(\%)\end{array}$ & $\begin{array}{l}\text { Argila } \\
\left(\mathrm{g} \mathrm{kg}^{-1}\right)\end{array}$ & $\begin{array}{c}\text { Densidade do solo } \\
\left(\mathrm{Mg} \mathrm{m}^{-3}\right)\end{array}$ \\
\hline & \multicolumn{12}{|c|}{ Latossolo Vermelho distrófico - Usina Santa Adélia } \\
\hline $\operatorname{Ap}(0,15 \mathrm{~m})$ & 5,6 & 23 & 10 & 3,6 & 18 & 13 & 0 & 17 & 51,6 & 67 & 285 & 1,305 \\
\hline $\mathrm{A}_{2}(0,37 \mathrm{~m})$ & 4,7 & 16 & 11 & 2,2 & 9 & 5 & 2 & 18 & 34,2 & 47 & 296 & 1,460 \\
\hline $\mathrm{BA}(0,56 \mathrm{~m})$ & 4,1 & 11 & 3 & 1,2 & 2 & 1 & 8 & 31 & 35,2 & 12 & 347 & 1,391 \\
\hline $\mathrm{BW}_{1}(0,96 \mathrm{~m})$ & 4,4 & 8 & 1 & 0,9 & 3 & 1 & 3 & 20 & 24,9 & 20 & 371 & 1,208 \\
\hline $\mathrm{BW}_{2}(0,96 \mathrm{~m}+)$ & 5,1 & 7 & 1 & 3,5 & 2 & 1 & 0 & 9 & 15,5 & 42 & 367 & 1,244 \\
\hline \multicolumn{13}{|c|}{ Latossolo Vermelho-Amarelo eutrófico - Usina São Luiz } \\
\hline $\operatorname{Ap}(0,2 \mathrm{~m})$ & 7,2 & 20 & 10 & 1,9 & 43 & 11 & 0 & 8 & 63,9 & 87 & 260 & 1,641 \\
\hline $\mathrm{BA}(0,44 \mathrm{~m})$ & 6,5 & 8 & 1 & 2,6 & 7 & 3 & 0 & 11 & 23,6 & 53 & 269 & 1,634 \\
\hline $\mathrm{BW}_{1}(0,81 \mathrm{~m})$ & 6,9 & 6 & 2 & 2,5 & 11 & 4 & 0 & 10 & 27,5 & 64 & 248 & 1,445 \\
\hline $\mathrm{BW}_{2}(0,81 \mathrm{~m}+)$ & 6,4 & 8 & 1 & 1,8 & 18 & 7 & 0 & 11 & 37,8 & 71 & 231 & 1,373 \\
\hline
\end{tabular}


quatro repetições. O N foi aplicado na forma de ureia, no sulco de plantio. Cada parcela experimental foi constituída de 48 sulcos, espaçados em $1,5 \mathrm{~m}$, com $15 \mathrm{~m}$ de comprimento.

$\mathrm{Na}$ USA, foi aplicado herbicida para dessecação da soqueira, e foram distribuídos $2 \mathrm{Mg} \mathrm{ha}^{-1}$ de calcário dolomítico, seguidos de aração (arado de aivecas), gradagem intermediária (28") e da abertura de sulcos para o plantio. Na USL, foi utilizada grade aradora (32"), para eliminação da soqueira, subsolagem, e foi feita a

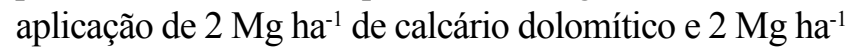
de gesso agrícola, seguida de grade aradora (32"), grade intermediária (28") e abertura de sulcos para o plantio. Os sulcos tiveram $0,35 \mathrm{~m}$ de profundidade, nos quais foram distribuídas 15 gemas viáveis por metro, além de $120 \mathrm{~kg} \mathrm{ha}^{-1}$ de $\mathrm{P}_{2} \mathrm{O}_{5}$ e $120 \mathrm{~kg} \mathrm{ha}^{-1}$ de $\mathrm{K}_{2} \mathrm{O}$, na forma de superfosfato triplo e cloreto de potássio, respectivamente. Foram aplicados inseticida e nematicida sobre as mudas, que foram cobertas mecanicamente com uma camada de $0,1 \mathrm{~m}$ de terra. O plantio foi realizado em 22/2/2005 na USL, e em 5/4/2005 na USA.

Em outubro de 2005 (USA e USL), em fevereiro de 2006 (USA e USL) e em junho (USL) e julho de 2006 (USA), foram realizadas amostragens da parte aérea e do sistema radicular da cultura. Para a amostragem de raízes foi utilizada sonda com $0,055 \mathrm{~m}$ de diâmetro interno (Sondaterra), até a profundidade de $0,6 \mathrm{~m}$. Foram coletadas duas amostras sobre a linha de plantio, duas a $0,3 \mathrm{~m}$ da linha e duas a $0,6 \mathrm{~m}$ da linha, de modo que as seis amostras representassem o perfil do solo explorado pelo sistema radicular (Figura 1).

A separação das raízes do solo foi realizada no campo, com peneiras de malha de $2 \mathrm{~mm}$. Teve-se o cuidado de coletar as raízes que eventualmente passaram pela peneira. Em laboratório, as raízes foram lavadas em água corrente, sobre peneiras com malha de $1 \mathrm{~mm}$ e, em seguida, secas em estufa a $65^{\circ} \mathrm{C}$ até a obtenção de massa constante, para determinação da umidade. Não foi considerada a massa de rizomas. O cálculo da massa de matéria seca de raízes foi realizado separadamente para as camadas de $0-0,3$ e 0,3-0,6 m, e posteriormente somadas, para extrapolar os valores para matéria seca de raízes por hectare até $0,6 \mathrm{~m}$, por meio da equação:

$\mathrm{MR}=\left[\left(\left(\left(\mathrm{M}_{\mathrm{A}} / 2\right) / \mathrm{Vs}\right) \times \mathrm{V}_{\mathrm{A}}\right)+\left(\left(\left(\mathrm{M}_{\mathrm{B}} / 2\right) / \mathrm{Vs}\right) \times \mathrm{V}_{\mathrm{B}}\right)+\left(\left(\left(\mathrm{M}_{\mathrm{C}} / 2\right) /\right.\right.\right.$ Vs) $\left.\left.x V_{C}\right)\right]$ x 1000 ,

em que: MR é a matéria seca de raízes, em $\mathrm{kg} \mathrm{ha}^{-1}$; $\mathrm{M}_{\mathrm{A}}, \mathrm{M}_{\mathrm{B}}$ e $\mathrm{M}_{\mathrm{C}}$ representam a matéria seca de raízes (g) obtidas nos locais A, B e C, respectivamente (Figura 1); Vs é o volume de solo amostrado pela sonda $\left(0,713 \mathrm{dm}^{3}\right)$; $\mathrm{V}_{\mathrm{A}}$ é o volume de solo $\left(\mathrm{dm}^{3} \mathrm{ha}^{-1}\right)$ representado pela faixa amostrada A, obtido por:

$\mathrm{V}_{\mathrm{A}}=\left(0,3 \mathrm{~m}_{\text {largura }} \times 0,3 \mathrm{~m}_{\text {profund }} \times 6.667 \mathrm{~m}_{\text {comprim }}\right) \times 1.000=$ $600.000 \mathrm{dm}^{3}$;

$V_{B}$ e $V_{C}$ representam o volume de solo $\left(\mathrm{dm}^{3} \mathrm{ha}^{-1}\right)$ representado pelas faixas amostradas $\mathrm{B}$ e $\mathrm{C}$, respectivamente, obtidos por:

$\mathrm{V}_{\mathrm{B} \mathrm{eC}}=\left(0,6 \mathrm{~m}_{\text {largura }} \times 0,3 \mathrm{~m}_{\text {profund }} \times 6.667 \mathrm{~m}_{\text {comprim }}\right) \times 1.000$ $=1.200 .000 \mathrm{dm}^{3}$.

Para a avaliação da parte aérea da cultura, foi coletada toda a planta (colmos, ponteiros e folhas secas) em $2 \mathrm{~m}$ de linha de plantio. Após a obtenção da massa de material fresco, as amostras foram trituradas em trituradora tipo forrageira, homogeneizadas e subamostradas para determinação da umidade ( 72 horas a $65^{\circ} \mathrm{C}$ ) e da massa de matéria seca.

A evapotranspiração potencial $\left(\mathrm{ET}_{0}\right)$ foi calculada pelo método de Penman-Monteith (Allen et al., 1998). A evapotranspiração potencial da cultura (ETPc) foi obtida pela multiplicação da $\mathrm{ET}_{0}$ pelo coeficiente da cultura (Kc), nos diversos estádios de crescimento, descritos em Doorenbos \& Kassan (1994), tendo-se substituído o Kc de 1,05, no período de máximo crescimento, pelo Kc de 1,25 , segundo modificações propostas por Allen et al. (1998) e confirmadas por Inman-Bamber \& McGlinchey (2003) para a cana-de-açúcar. A evapotranspiração real da

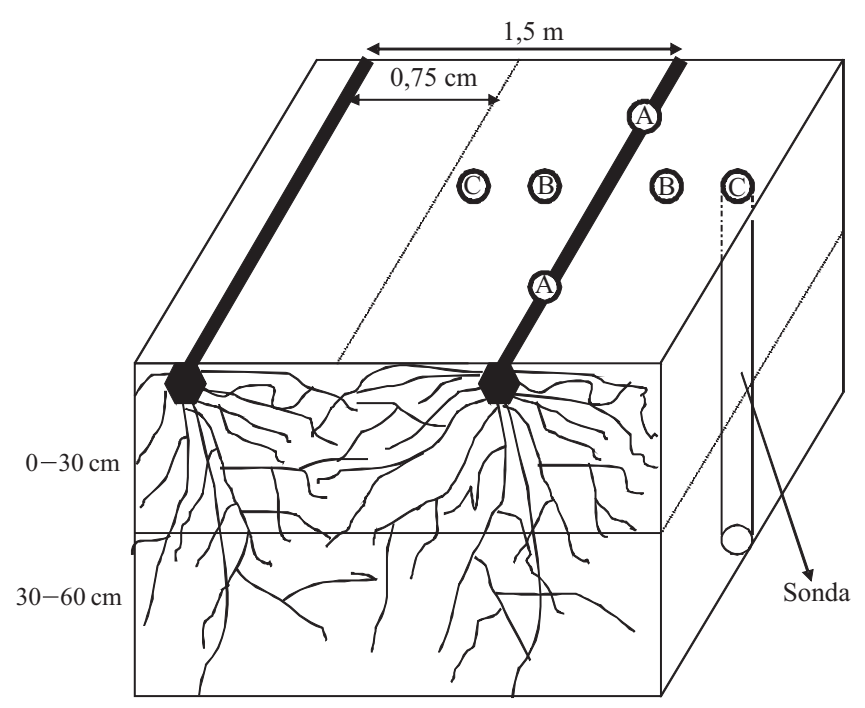

Figura 1. Esquema de amostragem do sistema radicular, com sonda, durante o ciclo da cana-planta. A, amostra sobre a linha; B, amostra a $30 \mathrm{~cm}$ da linha; C, amostra a $60 \mathrm{~cm}$ da linha. 
cultura (ETRc) foi obtida por meio do cálculo do balanço hídrico de cultura, por meio de planilhas eletrônicas (Rolim et al., 1998), tendo-se considerado a capacidade de água disponível (CAD, até $1 \mathrm{~m}$ ) de $72 \mathrm{~mm}$ para a USA e de $88 \mathrm{~mm}$ para a USL (Brito, 2006). Os dados climáticos foram obtidos em estações meteorológicas localizadas a cerca de 1.000 e $3.000 \mathrm{~m}$ da área experimental da USA e USL, respectivamente, enquanto a pluviosidade foi obtida em coletores instalados nas áreas experimentais.

Para cada experimento, os resultados obtidos por época de amostragem e por compartimento da planta foram submetidos à análise de variância e, quando o valor de $\mathrm{F}$ foi significativo $(1,5$ ou $10 \%$ de probabilidade), procedeu-se à análise de regressão, para determinar o efeito das doses de $\mathrm{N}$.

\section{Resultados e Discussão}

A matéria seca de raízes da cana-planta foi influenciada positivamente pela adubação nitrogenada seis meses após o plantio na USA, em outubro de 2005, e não exerceu efeito nas demais épocas (Tabela 2), enquanto na USL a fertilização nitrogenada proporcionou menor massa de raízes, em outubro, e maior massa nas demais épocas.

$\mathrm{Na}$ USA, a fertilização nitrogenada promoveu aumento significativo da massa da parte aérea em fevereiro (dez meses após o plantio), sem causar efeito nas demais épocas (Tabela 2). Contudo, na USL, a adição de $\mathrm{N}$ aumentou significativamente o crescimento da parte aérea em todas as épocas avaliadas, inclusive em outubro, quando a massa de raízes foi inferior nos tratamentos com $\mathrm{N}$.

A cana-de-açúcar apresentou padrões de crescimento diferenciados entre os locais, em relação à fertilização nitrogenada (Tabela 2). A falta de resposta a partir de fevereiro na USA pode estar associada aos resíduos culturais que foram incorporados ao solo na reforma do canavial, que continham cerca de $200 \mathrm{~kg} \mathrm{ha}^{-1}$ de $\mathrm{N}$ (Franco et al., 2007). As diferenças de respostas entre os locais podem estar relacionadas também à intensidade de revolvimento do solo na USA por ocasião da instalação da cultura, o que pode ter favorecido a mineralização da matéria orgânica do solo ou dos resíduos recém-incorporados, com consequente aumento do $\mathrm{N}$ disponível no solo.

Em avaliação realizada no final do ciclo, Trivelin et al. (2002) e Bologna-Campbell (2007) constataram aumento linear na massa da parte aérea e das raízes mais rizomas da cana-de-açúcar, em resposta à aplicação de nitrogênio. Sampaio et al. (1987) encontraram maior massa de raízes aos 6 e 16 meses após o plantio, na dose de $60 \mathrm{~kg} \mathrm{ha}^{-1}$ de $\mathrm{N}$ em relação à testemunha, e não encontraram diferença aos 11 meses após o plantio. Na USA, foi encontrado efeito da fertilização

Tabela 2. Fitomassa seca $\left(\mathrm{Mg} \mathrm{ha}^{-1}\right)$ de raízes $(\mathrm{R})$, na camada $0-0,6 \mathrm{~m}$ de profundidade, e da parte aérea (PA) da cana-planta, em diferentes épocas de amostragem, em razão da fertilização nitrogenada de plantio, na Usina Santa Adélia, com plantio em abril/2005, e na Usina São Luiz, com plantio em fevereiro/2005.

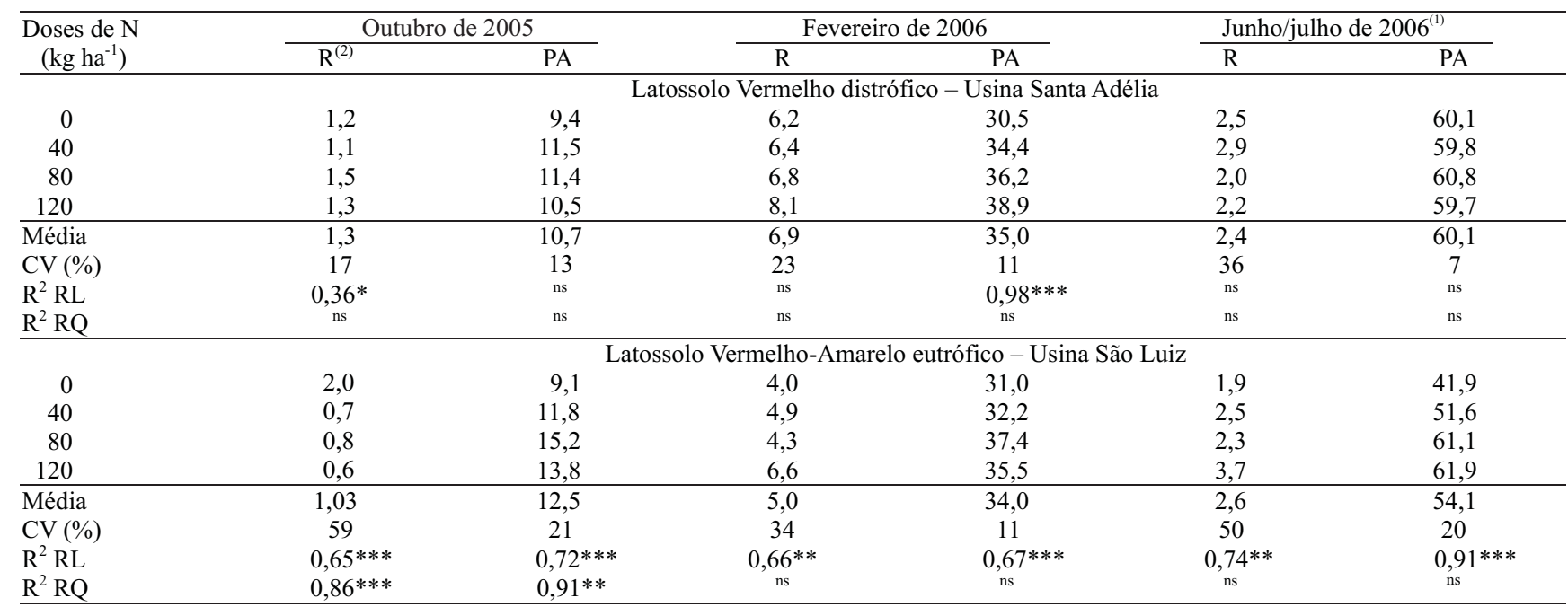

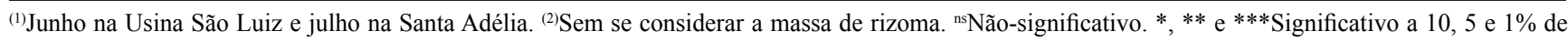
probabilidade, respectivamente. 
nitrogenada no crescimento das raízes somente na avaliação feita aos seis meses após o plantio, enquanto na USL esse efeito foi encontrado nas avaliações feitas aos 12 e 16 meses.

Em relação à diminuição da massa de raízes em outubro, em razão da aplicação de $\mathrm{N}$ na USL, porém com aumento da massa da parte aérea nessa mesma época, a hipótese é de que as raízes se desenvolveram próximas aos grânulos de fertilizante e obtiveram os nutrientes necessários para o crescimento da parte aérea com pequeno gasto energético para o crescimento das raízes. Por outro lado, nas parcelas que não receberam o fertilizante nitrogenado, houve maior gasto energético para o crescimento das raízes, fato que criou competição por fotoassimilados para o crescimento da parte aérea, que foi prejudicada nesse tratamento.
Em geral, a massa seca de raízes foi maior em fevereiro de 2006 do que nas demais épocas (Tabela 2). Esse fato pode ser resultado do perfilhamento da cultura, tendo em vista que a cana-de-açúcar apresenta alta densidade de perfilhos inicialmente, que decresce com o desenvolvimento da cultura. Isso ocorre devido à competição intraespecífica por fatores ambientais como temperatura, radiação solar, água e nutrientes. Esse comportamento dos perfilhos certamente relaciona-se com o crescimento radicular da cana-de-açúcar.

A massa da parte aérea aumentou em todos os períodos, o que evidencia que a morte parcial de raízes não interferiu no crescimento da parte aérea e concorda com as observações de Smith (1998). $\mathrm{O}$ período de maior acúmulo de massa de parte aérea foi de outubro a fevereiro, que corresponde ao estádio 2 (Figura 2), quando as condições climáticas
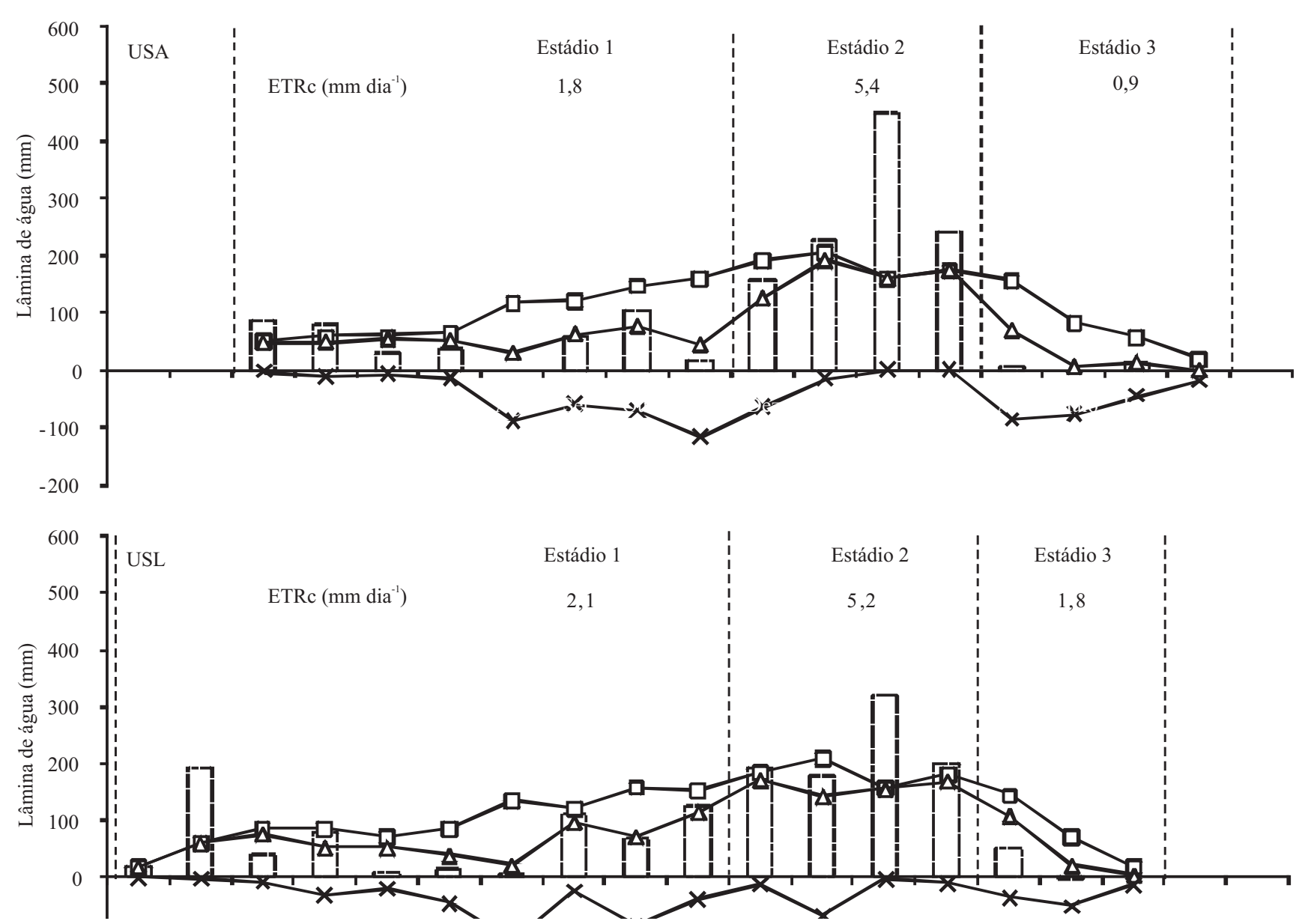

Figura 2. Evapotranspiração potencial da cultura (ETPc), evapotranspiração real da cultura (ETRc), índice pluviométrico e deficit hídrico, nas áreas das Usinas Santa Adélia (USA) e São Luiz (USL). 
foram mais favoráveis ao desenvolvimento da cultura, e proporcionaram maior evapotranspiração nas duas áreas.

A pluviosidade foi semelhante nos dois locais (1.522 $\mathrm{mm}$ na USA e $1.614 \mathrm{~mm}$ na USL), porém com distribuição ligeiramente distinta durante o desenvolvimento da cultura, o que contribuiu para produtividades diferenciadas entre as áreas. Dividindo-se o ciclo da cana-de-açúcar em três estádios - estabelecimento e crescimento inicial (do plantio até o fim de novembro), máximo crescimento (de dezembro ao fim de março) e maturação da cana (de abril até a colheita) -, observa-se que a evapotranspiração real da cultura (ETRc) foi ligeiramente distinta entre as áreas (Figura 2). Provavelmente, a maior produtividade obtida na USA (Tabela 2) deveu-se à maior ETRc na fase de máximo crescimento (período 2), em relação à ETRc da USL nesse mesmo período.

Nos dois experimentos, ficou evidente a relação estreita entre a quantidade de água armazenada no solo até $0,6 \mathrm{~m}$ (Brito, 2006) e a massa de raízes, em todas as épocas avaliadas (Figura 3). O maior armazenamento de água foi encontrado em fevereiro de 2006, mês em que a precipitação pluvial atingiu valores de $400 \mathrm{~mm}$ na USA e $300 \mathrm{~mm}$ na USL e que coincidiu com a época em que foi constatada a maior massa de raízes, durante o ciclo da canaplanta. A partir desse mês, a pluviosidade diminuiu, assim como o armazenamento de água no solo, o que favoreceu a diminuição da massa de matéria seca de raízes. A diminuição da massa de raízes pode estar relacionada, portanto, ao secamento do solo, além de fatores relacionados à fenologia da planta, que se encontra na fase final de crescimento e início da maturação.

Adinâmica de desenvolvimento do sistema radicular da cana-de-açúcar está associada à disponibilidade de água no solo (Vasconcelos, 2002; Smith et al., 2005). Isto indica que, em estudos que avaliam o sistema radicular de cana-de-açúcar, é importante avaliar também a umidade do solo, ou preferivelmente o armazenamento de água no solo (até a profundidade em que se pretende realizar o estudo das raízes), para auxiliar no entendimento da dinâmica de crescimento do sistema radicular da cultura.

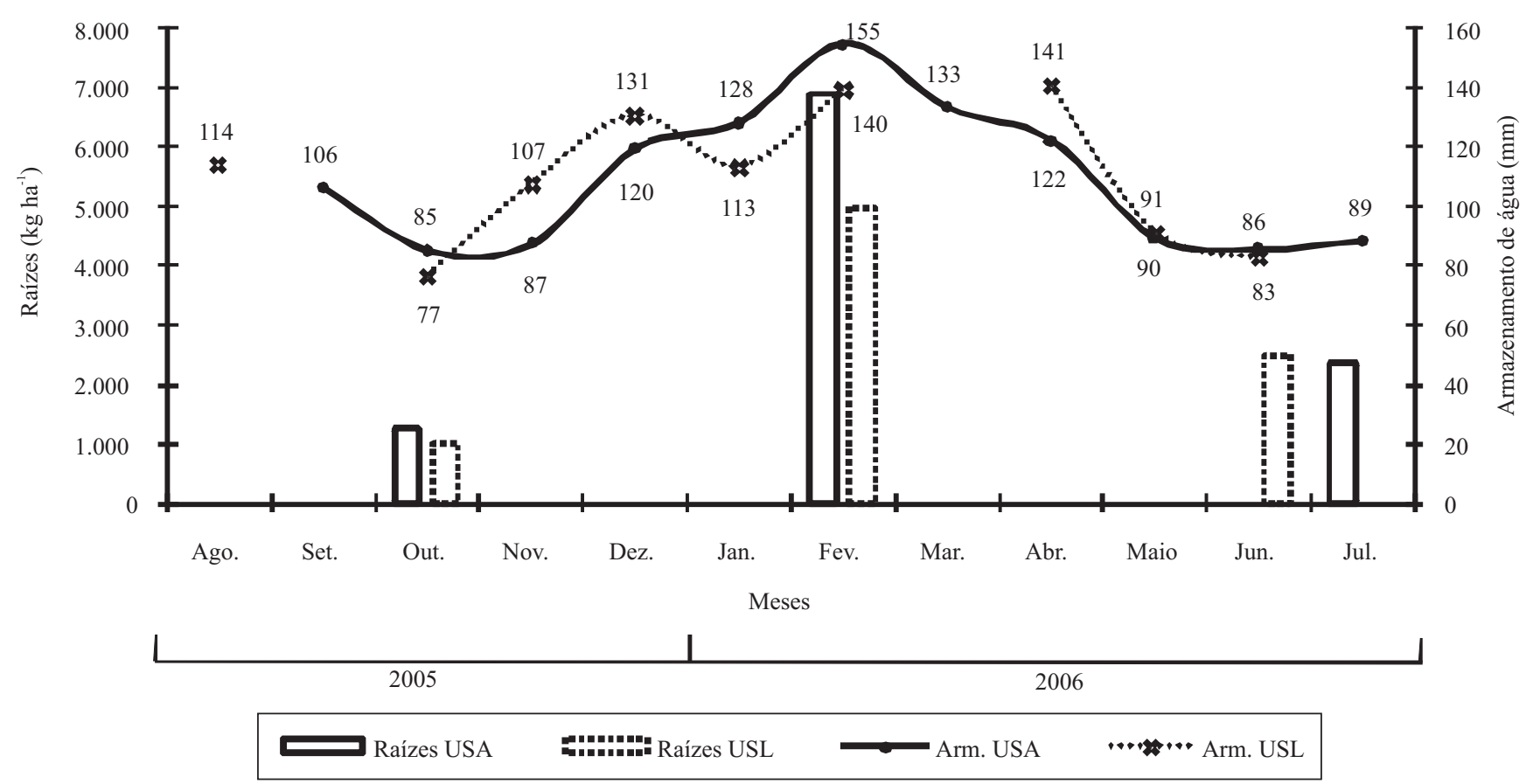

Figura 3. Armazenamento de água nos primeiros $0,6 \mathrm{~m}$ do solo e massa de matéria seca de raízes no ciclo da cana-planta na Usina Santa Adélia (USA), em Jaboticabal, SP, e na Usina São Luiz (USL), em Pirassununga, SP. Na USL, em setembro/2005 e em março/2006, não foi quantificado o armazenamento de água no solo. 


\section{Conclusões}

1. A adubação nitrogenada de plantio incrementa o crescimento de raízes e da parte aérea da cana-planta em Latossolo Vermelho-Amarelo eutrófico.

2. A adubação nitrogenada de plantio não incrementa o crescimento de raízes e da parte aérea da canaplanta em Latossolo Vermelho distrófico com grande quantidade de nitrogênio orgânico incorporado ao solo por meio de resíduos culturais.

3. Em cana-planta de ano e meio, a fase de maior desenvolvimento de raízes é de outubro a fevereiro.

\section{Agradecimentos}

Às Usinas Santa Adélia e São Luiz, por cederem as áreas experimentais e equipes de apoio; à Fundação de Amparo à Pesquisa do Estado de São Paulo, pelo financiamento do projeto e concessão de bolsa; ao Conselho Nacional de Desenvolvimento Científico e Tecnológico e à SN-Centro, pelo apoio financeiro; ao Centro de Tecnologia Canavieira, pelo auxílio na instalação, condução e colheita do experimento; ao acadêmico de Engenharia Agronômica Matheus Olivetti Trivelin, pelo auxílio no cálculo da evapotranspiração da cultura.

\section{Referências}

ALBUQUERQUE, G.A.C.; MARINHO, M.L. Adubação na região Norte-Nordeste. In: ORLANDO FILHO, J. (Coord.). Nutrição de adubação da cana-de-açúcar no Brasil. Piracicaba: Instituto do Açúcar e do Álcool, 1983. p.267-286.

ALLEN, R.G.; PEREIRA, L.S.; RAES, D.; SMITH, M. Crop evapotranspiration: guidelines for computing crop water requirements. Rome: FAO, 1998. 300p. (FAO Irrigation and Drainage Paper, 56).

AZEREDO, D.F. de; BOLSANELLO, J.; WEBER, H.; VIEIRA, J.R. Nitrogênio em cana-planta - doses e fracionamento. STAB, v.4, p.26-33, 1986.

BLAKE, G.R.; HARTGE, K.H. Bulk Density. In: KLUTE, A. (Ed.). Methods of soil analysis. Part 1. Physical and mineralogical methods. Madison: American Society of Agronomy \& Soil Science Society of America, 1986. p.363-376. (Agronomy Series, 9).

BOLOGNA-CAMPBELL, I.R. Balanço de nitrogênio e enxofre no sistema solo-cana-de-açúcar no ciclo de cana-planta. 2007. 110p. Tese (Doutorado) - Escola Superior de Agricultura Luiz de Queiroz, Piracicaba.

BRITO, A.S. Balanço de água em um Latossolo Vermelho cultivado com cana-de-açúcar. 2006. 82p. Dissertação (Mestrado) - Escola Superior de Agricultura Luiz de Queiroz, Piracicaba.

CANTARELLA, H.; RAIJ, B. van. Adubação nitrogenada no Estado de São Paulo. In: SANTANA, M.B.M. (Ed.). Adubação nitrogenada no Brasil. Ilhéus: Sociedade Brasileira de Ciência do Solo, 1985. p.47-49.
CANTARELLA, H.; TRIVELIN, P.C.O.; VITTI, A.C. Nitrogênio e enxofre na cultura da cana-de-açúcar. In: SIMPÓSIO SOBRE NITROGÊNIO E ENXOFRE NA AGRICULTURA BRASILEIRA, 2006, Piracicaba. Anais. Piracicaba: International Plant Nutrition Institute, 2007. p.355-392.

DOORENBOS, J.; KASSAN, A.H. Efeito da água no rendimento das culturas. Campina Grande: UFPB, 1994. 306p. (FAO. Estudos FAO Irrigação e Drenagem, 33).

FRANCO, H.C.J.; BOLOGNA, I.R.; FARONI, C.E.; VITTI, A.C.; TRIVELIN, P.C.O. Acúmulo de macronutrientes em cana-deaçúcar em função da adubação nitrogenada e dos resíduos culturais incorporados ao solo no plantio. Bragantia, v.66, p.699-674, 2007.

FRANCO, H.C.J.; VITTI, A.C.; FARONI, C.E.; CANTARELLA, H.; TRIVELIN, P.C.O. Estoque de nutrientes em resíduos culturais incorporados ao solo na reforma de áreas com cana-de-açúcar. STAB, v.25, p.32-36, 2007.

GEE, G.W.; OR, D. Particle-size analysis. In: DANE, J.H.; TOPP, C. (Ed.). Methods of soil analysis: physical methods. Madison: American Society of Agronomy, 2002. p.255-289.

INMAN-BAMBER, N.G.; McGLINCHEY, M.G. Crop coefficients and water use estimates for sugarcane based on long-term Bowen ratio energy balance measurements. Field Crops Research, v.83, p.125-138, 2003.

KORNDÖRFER, G.H.; VALLE, M.R.; MARTINS, M.; TRIVELIN, P.C.O. Aproveitamento do nitrogênio da uréia pela cana-planta. Revista Brasileira de Ciência do Solo, v.21, p.23-26, 1997.

ORLANDO FILHO, J.; RODELLA, A.A.; BELTRAME, J.A.; LAVORENTI, N.A. Doses, fontes e formas de aplicação de nitrogênio em cana-de-açúcar. STAB, v.17, p.39-41, 1999.

PRADO, R. de M. e; PANCELLI, M.A. Resposta de soqueiras de cana-de-açúcar à aplicação de nitrogênio em sistema de colheita sem queima. Bragantia, v.67, p.951-959, 2008.

RAIJ, B. van; ANDRADE, J.C. de; CANTARELLA, H.; QUAGGIO, J.A. (Ed.). Análise química para avaliação da fertilidade de solos tropicais. Campinas: Instituto Agronômico, 2001. 285p.

ROLIM, G.S.; SENTELHAS, P.C.; BARBIERI, V. Planilhas no ambiente EXCEL ${ }^{\mathrm{TM}}$ para os cálculos de balanços hídricos: normal, sequencial, de cultura e de produtividade real e potencial. Revista Brasileira de Agrometeorologia, v.6, p.133-137, 1998.

SAMPAIO, E.V.S.B.; SALCEDO, I.H.; CAVALCANTI, F.J.A. Dinâmica de nutrientes em cana-de-açúcar. III: conteúdo de nutrientes e distribuição radicular no solo. Pesquisa Agropecuária Brasileira, v.22, p.425-431, 1987.

SANTOS, H.G. dos; JACOMINE, P.K.T.; ANJOS, L.H.C. dos; OLIVEIRA, V.A. de; OLIVEIRA, J.B. de; COELHO, M.R.; LUMBRERAS, J.F.; CUNHA, T.J.F. (Ed.). Sistema brasileiro de classificação de solos. 2.ed. Rio de Janeiro: Embrapa Solos, 2006. $306 \mathrm{p}$.

SMITH, D.M.; INMAN-BAMBER, N.G.; THORBURN, P.J. Growth and function of the sugarcane root system. Field Crops Research, v.92, p.169-183, 2005.

SMITH, J.P. Studies on the relation between root growth and shoot growth of sugarcane.1998. 132p. Thesis (M.Sc.) - James Cook University, Townsville. 
THORBURN, P.J.; DART, I.K.; BIGGS, I.M.; BAILLIE, C.P.; SMITH, M.A.; KEATING, B.A. The fate of nitrogen applied to sugarcane by trickle irrigation. Irrigation Science, v.22, p.201209, 2003.

TRIVELIN, P.C.O.; VITTI, A.C.; OLIVEIRA, M.W.; GAVA, G.J.C.; SARRIÉS, G.A. Utilização de nitrogênio e produtividade da cana-de-açúcar (cana-planta) em solo arenoso com incorporação de resíduos da cultura. Revista Brasileira de Ciência do Solo, v.26, p.637-646, 2002.

VASCONCELOS, A.C.M. Desenvolvimento do sistema radicular e da parte aérea de socas de cana-de-açúcar sob dois sistemas de colheita: crua mecanizada e queimada manual. 2002. 140p.
Tese (Doutorado) - Faculdade de Ciências Agrárias e Veterinárias, Jaboticabal.

VITTI, A.C.; TRIVELIN, P.C.O.; GAVA, G.J.C.; PENATTI, C.P.; BOLOGNA, I.R.; FARONI, C.E.; FRANCO, H.C.J. Produtividade da cana-de-açúcar relacionada ao nitrogênio residual da adubação e do sistema radicular. Pesquisa Agropecuária Brasileira, v.42, p.249-256, 2007.

ZAMBELLO JÚNIOR, E.; AZEREDO, D.F. Adubação na região Centro-Sul. In: ORLANDO FILHO, J. (Coord.). Nutrição de adubação da cana-de-açúcar no Brasil. Piracicaba: Instituto do Açúcar e do Álcool, 1983. p.289-313.

Recebido em 10 de junho de 2008 e aprovado em 19 de março de 2009 